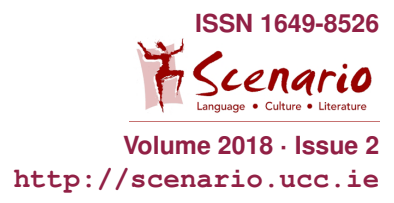

Short Film - 6th Scenario Forum Symposium

\title{
A short film documenting the 6th SCENARIO FORUM SYMPOSIUM 2018 (University of Hanover, 21-22 September 2018)
}

\section{Marwen Heni}

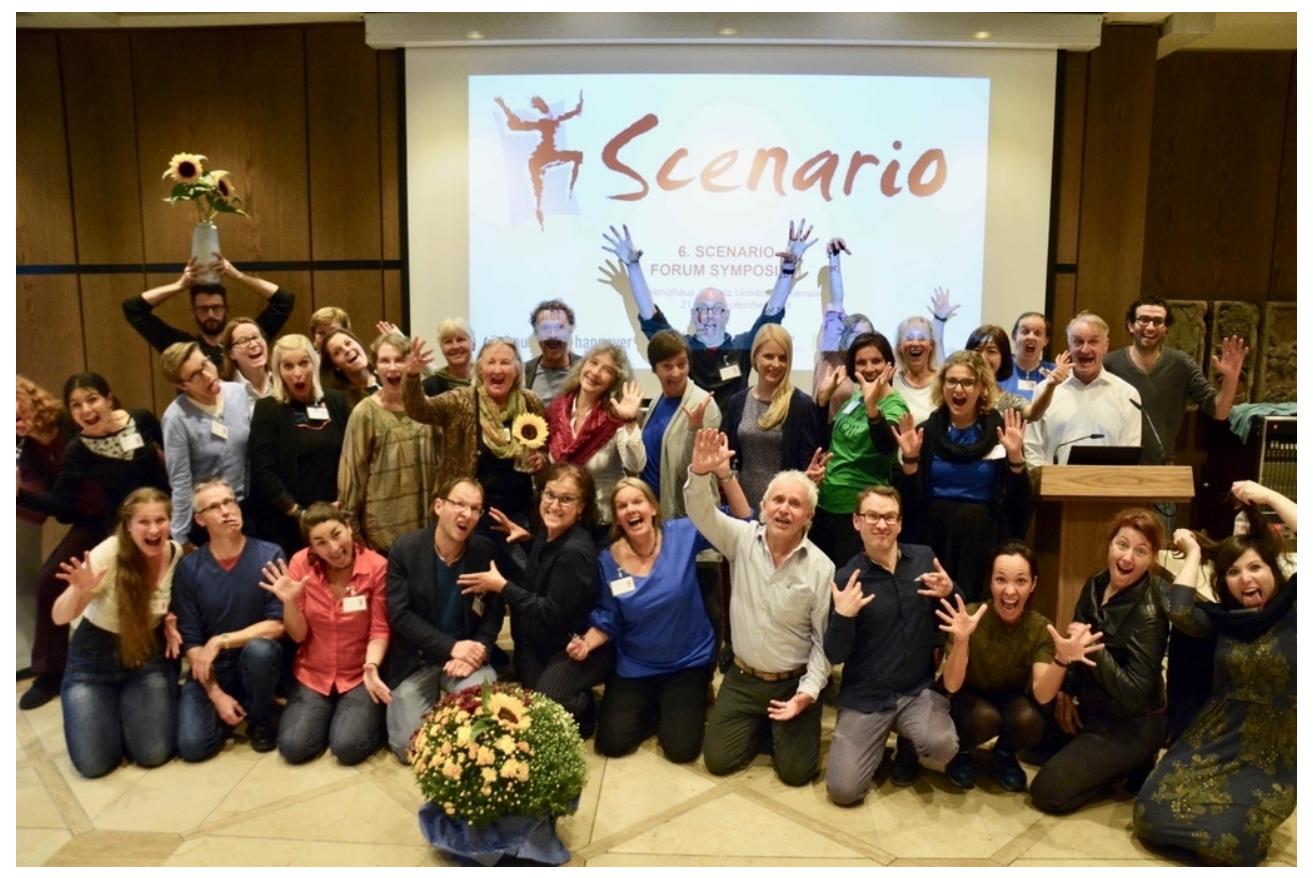

This clip will evoke and inspire: for those who were at the symposium (University of Hanover, September 21-22, 2018), it will no doubt bring back the memories, the connections, the 'AHA-moments'. For those who could not make it, it is a great opportunity to catch up on key issues of the symposium.

The film can be viewed on YouTube at: https://youtu.be/GV1XcfVM2rE. 